\title{
RNAi-mediated downregulation of urokinase plasminogen activator and its receptor in human meningioma cells inhibits tumor invasion and growth
}

\author{
SHAKUNTALA KONDRAGANTI ${ }^{1}$, CHRISTOPHER S. GONDI ${ }^{1}$, IAN McCUTCHEON ${ }^{4}$, \\ DZUNG H. DINH ${ }^{2}$, MEENA GUJRATI ${ }^{3}$, JASTI S. RAO ${ }^{1,2}$ and WILLIAM C. OLIVERO ${ }^{2}$ \\ ${ }^{1}$ Program of Cancer Biology, Department of Biomedical and Therapeutic Sciences, and Departments of \\ ${ }^{2}$ Neurosurgery, and ${ }^{3}$ Pathology, University of Illinois College of Medicine, Peoria, IL; \\ ${ }^{4}$ University of Texas M.D. Anderson Cancer Center, Houston, TX, USA
}

Received December 12, 2005; Accepted February 2, 2006

\begin{abstract}
In recent years, RNA interference (RNAi) has emerged as an effective method to target specific genes for silencing. Several groups are actively exploring the use of small interfering RNA (siRNA) for therapeutic applications to treat cancer. Our previous studies have demonstrated the inhibition of various proteases, including serine proteases, cysteine proteases and matrix metalloproteases, via RNA interference (RNAi) in gliomas. Similar to gliomas, malignant meningiomas also exhibit elevated protease levels in comparison to normal brain and benign meningiomas. Here, we used siRNA to simultaneously target urokinase plasminogen activator (uPA) and its receptor, uPAR. A human CMV promoter-driven mammalian expression vector ( $p U 2$ ) was used to produce hairpin double-stranded RNA (hp RNA) to target uPA and uPAR. As determined by Western blotting and fibrin zymography, pU2 effectively inhibited UPAR protein levels and uPA enzymatic activity in meningioma cells (IOMM-Lee). In vitro studies (Matrigel invasion and spheroid migration)
\end{abstract}

Correspondence to: Dr W.C. Olivero, Department of Neurosurgery, University of Illinois College of Medicine, P.O. Box 1649, Peoria, IL 61656, USA

E-mail: olib@uic.edu

Abbreviations: siRNA, small interfering RNA; RNAi, RNA interference; dsRNA, double stranded RNA; hpRNA, hairpin RNA; $\mathrm{CMV}$, cytomegallovirus; $\mathrm{uPA}(\mathrm{R})$, urokinase plasminogen activator (receptor); MMP, matrix metalloprotease; pU2, plasmid expressing hpRNA for uPAR and uPA; pU, plasmid expressing hpRNA for uPA; pUR, plasmid expressing hpRNA for uPAR; EV, empty vector; SV, scrambled vector; DiI, 1'-dioctadecyl-3,3,3',3'-tetramethylindocarbocyanineperchlorate; DiO, 3,3'-dioctadecyloxacarbocyanine perchlorate; ECM, extracellular matrix; FRBA, fetal rat brain aggregate

Key words: migration, invasion, meningioma, siRNA revealed reduced meningioma cell invasion and migration. Intratumoral injections of the plasmid vector expressing siRNA for UPA and UPAR resulted in regression of pre-established, subcutaneous tumors in mice. In addition, in vivo studies of mice injected with pU2-transfected meningioma cells revealed inhibition of intracranial tumor formation. These findings suggest that siRNA can be used as a potent and specific therapeutic tool for the treatment of malignant meningiomas in humans.

\section{Introduction}

RNA interference (RNAi) is a genetic interference phenomenon in which double-stranded RNA (dsRNA) are processed to siRNA using Dicer, a cellular ribonuclease III, which generates duplexes of approximately 21 nucleotides with 3 overhangs $(1,2)$. These siRNA are then incorporated into a silencing complex called RISC. When introduced into cells, dsRNA lead to the degradation of mRNA, which contain regions homologous to the triggering dsRNA. RNAi was initially seen in C. elegans $(3,4)$ and Drosophila $(5,6)$ as a protective mechanism against invasion of foreign genes. Elbashir et al (1) first reported that small interfering RNA (siRNA) (19-23 nucleotides) can effectively induce RNAi in mammalian cells. siRNA cause gene silencing at the post-transcriptional level in a sequence-specific manner without any apparent cell toxicity (7). Furthermore, compared to antisense oligonucleotides, very few molecules of siRNA are needed for gene silencing (8). For all of these reasons, RNAi is a novel, potent alternative to other gene therapies.

Meningiomas are primary brain tumors arising from the meninges (linings of brain) and they constitute approximately $20 \%$ of brain tumors. They range from benign, which are more common, to atypical and anaplastic (malignant) $(9,10)$. Malignant meningiomas are highly infiltrative and invade brain, dura-mater and bone. In general, the tumors cannot be completely excised, even after radiotherapy. Currently, no effective chemotherapy exists. As a consequence, meningiomas present a therapeutic challenge.

Typical of many malignant tumor types, proteases play a major role in the ability of meningioma cells to invade 
other tissues. Tumor cell invasion is a complex phenomenon involving interactions between tumor cells, normal stromal cells, and the extracellular matrix (ECM), as well as the subsequent degradation of the ECM and tumor cell migration (11). Invasive tumor cells are known to produce ECMdegrading enzymes, such as the plasminogen activators (PAs), which belong to the family of serine proteases. Plasminogen activators convert plasminogen into plasmin and further regulate a cascade of proteolytic events. The effect of plasmin appears to be either the direct degradation of ECM components (e.g. fibronectin, laminin and proteoglycans) or an indirect effect via the activation of latent forms of matrix metalloproteinases (MMPs), which hydrolyze plasminresistant collagenous elements. Our previous studies of human meningioma samples have established the increased expression of UPA, MMP-2 and MMP-9 (12).

Urokinase plasminogen activator ( $\mathrm{uPA}$ ) is a $55-\mathrm{kDa}$ serine protease implicated in tumor cell invasion, angiogenesis and progression (13). uPA is secreted as an inactive precursor and can be activated into its active, single chain enzyme form by a variety of proteases, including plasmin, cathepsins B \& L, and trypsin-like enzymes (14). Active uPA binds to its high affinity receptor, uPAR (CD-87), a 45- to 55-kDa cysteinerich glycoprotein, which is covalently attached to the plasma membrane via glycosyl phosphatidylinositol (15). uPA, when bound to its specific cell surface receptor UPAR, efficiently converts plasminogen to the active serine protease plasmin (16), which then initiates the destruction of various ECM proteins. Through interactions between UPAR and integrins, as well as ECM components such as vitronectin, uPA aids in cell migration and adhesion $(17,18)$. Thus, with or without involving the proteolytic activity of uPA, the uPA-uPAR system plays an important role in a variety of physiological and pathophysiological processes requiring cell movement, including wound healing, angiogenesis and tumor metastasis $(13,19,20)$. Previous findings suggest the involvement of the uPA-uPAR system in chemotaxis $(21,22)$ and in the activation of intracellular signaling pathways leading to enhanced cell proliferation, adhesion and migration (23-25). Thus, the uPA-uPAR system participates in the regulation of a wide range of cellular activities $(26,27)$.

It is well documented that high levels of UPA and UPAR are associated with poor prognosis in many cancers, and that mice deficient in uPA have smaller, less hemorrhagic tumors (28). Considerable evidence of the elevated levels of uPA and UPAR in tumor tissue demonstrates their fundamental role in tumor invasion and metastasis and provides a rationale for novel therapeutic strategies. Several technical methods affecting tumor growth and metastasis, such as antisense oligodeoxynucleotides, adenoviral vectors, monoclonal antibodies, toxins, natural and synthetic inhibitors, linear and cyclic uPA-derived peptides etc. targeting the UPA-UPAR system in cancer patients at the gene and protein level, have been explored (29).

We have previously reported elevated levels of uPA in human meningioma tissue samples (12). We have also shown that antisense UPA stable clones (30) and adenovirus-mediated transduction (Ad-uPAR) of the uPAR antisense gene construct (31) resulted in less invasion and no tumor formation in nude mice. Similarly, intracranial injection of glioma cells with the Ad-uPAR-uPA antisense bicistronic construct inhibited invasiveness and tumorigenicity (32). RNAi for MMP-9 and cathepsin B (33) and RNAi for cathepsin-B and uPAR (34) reduced glioma cell invasion and angiogenesis both in vitro and in vivo. We report here that RNAi for uPA and UPAR reduced meningioma cell invasion and caused tumor regression in nude mice. Hence, siRNA may have therapeutic importance in the treatment of human meningiomas.

\section{Materials and methods}

Construction of hpRNA expressing plasmid. A pcDNA 3 plasmid with a human cytomegalovirus (CMV) promoter was used to construct the hpRNA-expressing vector. The following sequences were used: for uPA, agcttGagagccetgctggcgcgccat atataatggcgcgccagcagggctctca from 346 to 367 bases, and for uPAR, tccTacagcagtggagagcgattatatataataatcgctctccactgctg tag from 77 to 98 bases. Inverted repeat sequences were synthesized for both uPA and uPAR (HindIII sites at the 5' and 3 ' ends).

Cell culture and transfection conditions. An established human meningioma cell line, IOMM-Lee (kindly provided by Dr Ian McCutcheon, U.T. M.D. Anderson Cancer Center, Houston, TX), was used in the current study. The cells were maintained in Dulbecco's modified Eagle's medium (Mediatech, Herndon, VA) supplemented with $10 \%$ fetal bovine serum, $100 \mu \mathrm{g} / \mathrm{ml}$ streptomycin and $100 \mathrm{U} / \mathrm{ml}$ penicillin (Invitrogen, Carlsbad, $\mathrm{CA}$ ) in a humidified atmosphere containing $5 \% \mathrm{CO}_{2}$ at $37^{\circ} \mathrm{C}$. IOMM cells were transfected with EV, SV, pU, pUR or pU2 using the Lipofectamine reagent (Invitrogen, Grand Island, $\mathrm{NY}$ ) as per the manufacturer's instructions. After transfection, cells were incubated in serum-containing medium for $48 \mathrm{~h}$.

Immunoblot analysis. After transfection of IOMM-Lee cells with mock, EV, SV, pU, pUR or pU2 for $48 \mathrm{~h}$, cells were collected and total cell lysates were prepared by incubating the cells in RIPA buffer $(150 \mathrm{mM} \mathrm{NaCl}, 1 \%$ Triton X-100, $1 \%$ sodium deoxycholate, $0.1 \%$ SDS, $20 \mathrm{mM}$ EDTA and $50 \mathrm{mM}$ Tris, $\mathrm{pH} 7.4$ ) for $1 \mathrm{~h}$ at $41^{\circ} \mathrm{C}$. In total, $30 \mathrm{mg}$ of protein from each sample was subjected to $12 \%$ SDS-Tris-glycine gel electrophoresis and transferred onto a nitrocellulose membrane (Bio-Rad Labs, CA). The membrane was blocked with $5 \%$ non-fat dry milk, $0.1 \%$ Tween-20 in PBS for $1 \mathrm{~h}$. The primary antibodies employed were directed against uPAR (R\&D Systems, Minneapolis, MN) and uPA (Biomeda, Foster City, CA) followed by secondary antibodies (HRPconjugated goat anti-mouse IgG+IgM, Biomeda). The membranes were developed according to the manufacturer's protocol (Amersham, Arlington Heights, IL). For loading control, the membranes were stripped and probed with monoclonal antibodies for B-actin.

Zymography. IOMM-Lee cells were transfected with mock, $\mathrm{EV}, \mathrm{SV}, \mathrm{pU}, \mathrm{pUR}$ and pU2. Conditioned media were collected and zymography performed as described previously $(30,35)$. The samples were subjected to SDS-PAGE with $10 \%$ gels that contained fibrinogen and plasminogen. The gels were then washed twice with $2.5 \%$ Triton X-100 for 30 min each, incubated with $0.1 \mathrm{M}$ glycine buffer $(\mathrm{pH} 7.5)$ at $37^{\circ} \mathrm{C}$ overnight, stained with amido black and then destained. 


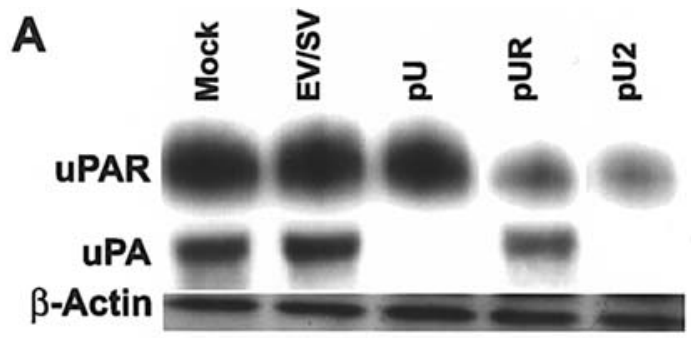

B

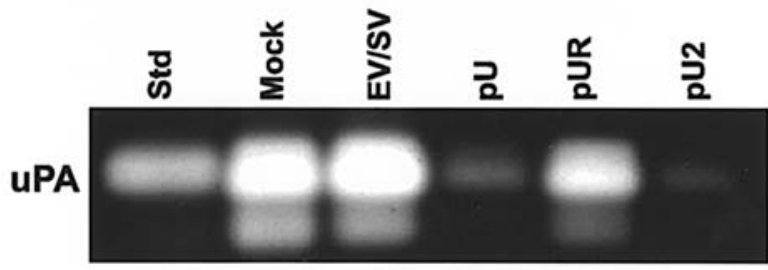

Figure 1. RNA interference decreased UPAR and UPA levels in IOMM-Lee cells. Total cell lysates and conditioned media collected from cells were transfected with mock, EV/SV, pUR, pU or pU2. Protein $(10 \mu \mathrm{g})$ was separated on $12 \%$ SDS-PAGE and immunoblotted with anti-uPAR antibody (A). Conditioned media $(50 \mu \mathrm{g})$ was separated on $12 \%$ SDS-PAGE and immunoblotted with anti-uPA antibody (A). B-actin antibody was simultaneously immunoprobed for loading control. Fibrin zymography was performed as described in Materials and methods with $1 \mu \mathrm{g}$ of conditioned media to detect uPA activity (B).

Matrigel invasion assay. In vitro invasion of meningioma cells was measured by the invasion of cells through Matrigelcoated (Collaborative Research Inc., Boston, MA) transwell inserts (Costar, Cambridge, MA) according to a previously described procedure (36). Briefly, 12-well transwell inserts with an 8-mm pore size were coated with a final concentration of $1 \mathrm{mg} / \mathrm{ml}$ of Matrigel in cold serum-free DMEM. Cells were trypsinized and $200 \mathrm{ml}$ of cell suspension $\left(1 \times 10^{6}\right.$ cells/ $\mathrm{ml}$ ) from each treatment were added to triplicate wells. After a 24-h incubation period, the cells that passed through the filter into the lower wells were quantitated by counting random fields and expressed as a percentage of the sum of the cells in the upper and lower wells (37).

Spheroid migration. A suspension of $5 \times 10^{4}$ cells in $100 \mu 1$ of Dulbecco's modified Eagle's medium was seeded on 96-well ultra low attachment culture plates (Costar) and continuously shaken at 40-60 r.p.m for 5 days until spheroids formed. Spheroids were then transfected with mock, EV, SV, pU, pUR or pU2 and cultured for $48 \mathrm{~h}$. Seveny-two hours after transfection, spheroids were placed in each well of vitronectincoated $(50 \mathrm{mg} / \mathrm{ml}) 8$-well chamber slides (Lab-Tek) and cultured with $200 \mathrm{ml}$ of serum-free medium. Spheroids were incubated at $37^{\circ} \mathrm{C}$ for $24 \mathrm{~h}$, after which the spheroids were fixed and stained with Hema 3 and photographed. Migration of cells from spheroids to monolayers was measured using a microscope calibrated with a stage and ocular micrometer and used as an index of cell migration.

Three-dimensional spheroid invasion model. Multicellular spheroids were cultured in 96-well low attachment plates (Costar) prepared in DMEM. Briefly, 5x10 cells were suspended in $100 \mathrm{ml}$ of medium, seeded onto 96-well ultra low attachment plates and continuously shaken at 40-60 rpm for 5 days. The spheroids were then transfected and stained with the fluorescent dye, Dil. Similarly, 18-day-old fetal rat brain cells were seeded and cultured for 21 days and stained with the fluorescent dye, DiO. The tumor spheroids and fetal rat brain aggregates were then co-cultured and, at various intervals, serial 1-mm optical sections were obtained with the aid of a confocal laser-scanning microscope. DiI and DiO fluorescence (Molecular Probes Inc., Eugene, OR) were detected by an argon laser at $488 \mathrm{~nm}$ with a band pass filter at 520-560 nm (DiI) and a helium/neon laser at $543 \mathrm{~nm}$ with a long pass filter at $590 \mathrm{~nm}(\mathrm{DiO})$. As described previously, the remaining volumes of rat brain aggregates and tumor spheroids were quantitated at 24, 48 and $72 \mathrm{~h} \mathrm{(36).}$

Subcutaneous tumors. IOMM-Lee cells $\left(5 \times 10^{6}\right)$ were trypsinized and resuspended in $100 \mu 1$ of serum-free DMEM and injected into the right flank of an athymic female nude mouse. When the tumors reached a size of 4-5 mm (usually in 7-10 days), mock-, EV-, SV-, pU-, pUR- or pU2-transfected cells were injected intratumorally at a dose of $60 \mu \mathrm{g} /$ mouse on alternate days for a total of five doses. The mice were observed for 4 weeks, after which the tumors were excised and photographed. Tumor volumes were quantified and graphically represented.

Intracerebral injection. To examine the in vivo effects of RNAi in meningiomas, we transfected IOMM-Lee cells with mock, $\mathrm{EV} / \mathrm{SV}, \mathrm{pU}, \mathrm{pUR}$ or pU2. Cells $\left(0.5 \times 10^{6}\right)$ were trypsinized, resuspended in serum-free medium, and injected into the brains of athymic female nude mice. Thirty mice were used with five per treatment group. The mice were anesthetized with an i.p. injection consisting of $50 \mathrm{mg} / \mathrm{kg}$ ketamine and $25 \mathrm{mg} / \mathrm{kg}$ xylazine and injected intracerebrally with a $10-\mathrm{ml}$ aliquot $\left(0.5 \times 10^{6}\right)$ of the specified cell type with the aid of a stereotactic frame as described previously (36). After 4 weeks, the mice were sacrificed via intracardiac perfusion, first with PBS and then with formaldehyde. The brains were removed and embedded in paraffin as per standard protocol. Sections were prepared and stained with H\&E. Serial sections of the paraffin blocks were taken and approximate tumor volume measured as a product of the tumor area and the depth of the tumor.

\section{Results}

pU2 transfection downregulates $u P A R$ protein levels and decreases UPA activity in IOMM-Lee cells. Tumor cell invasion is a characteristic feature of most malignant tumors. uPA and UPAR are serine proteases which play important roles in ECM degradation and, as such, aid in tumor cell invasion. We targeted these genes using a bicistronic vector expressing siRNA for uPAR (77-98 bases of human uPAR mRNA) and uPA (346-367 bases of human uPA mRNA) under the control of a human cytomegalovirus (CMV) promoter. As determined by Western blotting, transfection of IOMM-Lee cells with pUR and pU2 inhibited uPAR protein levels as compared to mock- and empty/scrambled vector-transfected controls (Fig. 1A). Immunoblotting with conditioned medium from $\mathrm{pU}$ - and $\mathrm{pU} 2$-transfected IOMM-Lee cells revealed a decrease in uPA protein levels (Fig. 1A). B-actin levels determined that equal quantities of protein were loaded in each lane. Fibrin zymography results revealed a reduction in 

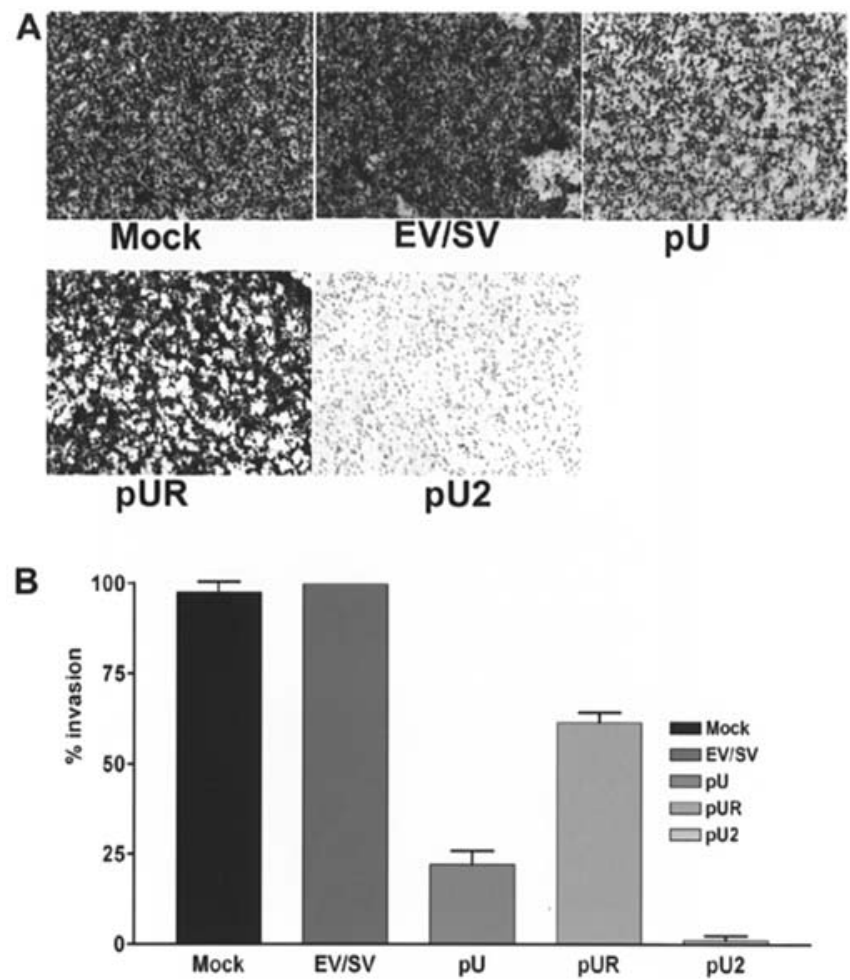

Figure 2. Matrigel invasion of IOMM-Lee cells transfected with mock, $\mathrm{EV} / \mathrm{SV}, \mathrm{pU}, \mathrm{pUR}$ and pU2. $1 \times 10^{6}$ transfected cells were seeded on Matrigelcoated 12-well transwell inserts (8- $\mu \mathrm{m}$ pores) and allowed to invade. After $24 \mathrm{~h}$, cells that had passed through the filter into the lower wells were fixed and stained with Hema 3 and photographed (A). Percentage of invasion was quantitated as described in Materials and methods (B).

uPA activity in pU- and pU2-transfected cells as compared to mock-, EV/SV- and pUR-transfected cells (Fig. 1B). The decreases in UPAR expression and UPA activity are more pronounced in pU2-transfected cells, indicating that the bicistronic construct is more effective than either of the single constructs.

pU2 transfection decreases invasion of IOMM-Lee cells. To study the effect of siRNA on the invasion capacity of meningiomas, $1 \times 10^{6}$ IOMM-Lee cells transfected with mock, $\mathrm{EV} / \mathrm{SV}, \mathrm{pU}, \mathrm{pUR}$ or pU2 were seeded in the upper chambers of Matrigel-coated transwells. Twenty-four hours later, the cells which had migrated to the lower chambers were stained. Invasion of pU-, pUR- and pU2-transfected cells was low compared to mock- and EV/SV-transfected cells (Fig. 2A). Quantitative determination of invasion showed that only $0.3 \%$ of pU2-transfected cells invaded to the lower side of the membrane, $23 \%$ of pU-transfected, and $69 \%$ of pURtransfected cells (Fig. 2B). As determined by the Matrigel invasion assay, inhibition of meningioma cell invasion was much higher in cells transfected with the bicistronic construct than either of the single constructs.

pU2 transfection of IOMM-Lee spheroids decreases migration. Active cellular migration is essential for tumor invasion and metastasis. A number of factors, such as growth factors and cytokines, modulate migration. We performed a spheroid migration assay to study whether siRNA-mediated inhibition of UPA and UPAR can influence migration of meningioma
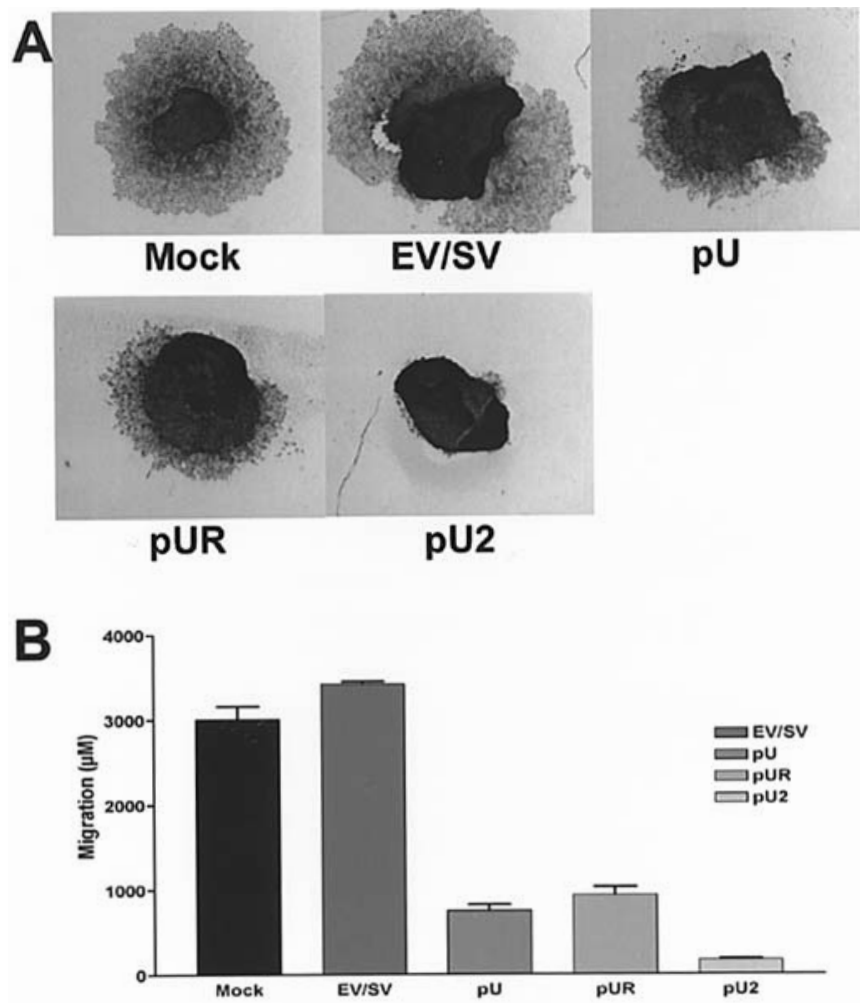

Figure 3. Spheroid migration by IOMM-Lee cells transfected with mock, EV/SV, pU, pUR and pU2. Spheroids of 100-200 microns were prepared by seeding $5 \times 10^{4}$ cells on 96 -well low attachment plates by continuous shaking at $60 \mathrm{rpm}$. The spheroids were transfected with mock, EV/SV, pU, pUR or pU2. Seventy-two hours later, the spheroids were placed on vitronectin-coated 8 -well chamber slides and allowed to migrate. After $48 \mathrm{~h}$, the spheroids were then fixed and stained by Hema 3 (A). Spheroid migration was quantified and graphically represented (B).

cells. Multicellular meningioma spheroids grown in 96-well low attachment plates (100-200 $\mu \mathrm{m}$ in size) were transfected with mock, EV/SV, pU, pUR, or pU2. Seventy-two hours later, spheroids were transferred to vitronectin-coated 8-well chamber slides and allowed to migrate for $48 \mathrm{~h}$. The migrating capacity of the mock- and EV/SV-transfected spheroids was significantly higher than the spheroids transfected with pU, pUR and pU2 (Fig. 3A). Quantitative analysis (Fig 3B) showed that the control mock- and EV/SV-transfected spheroids migrated $2872 \pm 30 \mu \mathrm{M}$ and $3200 \pm 25 \mu \mathrm{M}$. pURtransfected spheroids migrated more than pU-transfected spheroids $(872 \pm 20 \mu \mathrm{M}$ and $780 \pm 35 \mu \mathrm{M}$, respectively), and pU2-transfected spheroids migrated the least $(20 \pm 5 \mu \mathrm{M})$.

pU2 transfection of IOMM-Lee spheroids decreases invasion. To study the siRNA effect of UPA and UPAR on IOMM-Lee cell invasion in a three dimensional system, meningioma spheroids stained with fluorescent dye DiI and fetal rat brain aggregates stained with fluorescent dye $\mathrm{DiO}$ were co-cultured. Staining of the cells with these dyes allows better visualization and characterization of the invasive pattern than other in vitro invasion assays. The advantage of this model is that tumor cells grown in three-dimensional culture closely resemble those of in vivo tumors. Tumor spheroids transfected with mock, EV/SV and pU2 were confronted with rat fetal brain aggregates in a 96-well agar-coated plate and observed at 24-, 48- and 72-h intervals. Co-culture assays revealed that tumor 


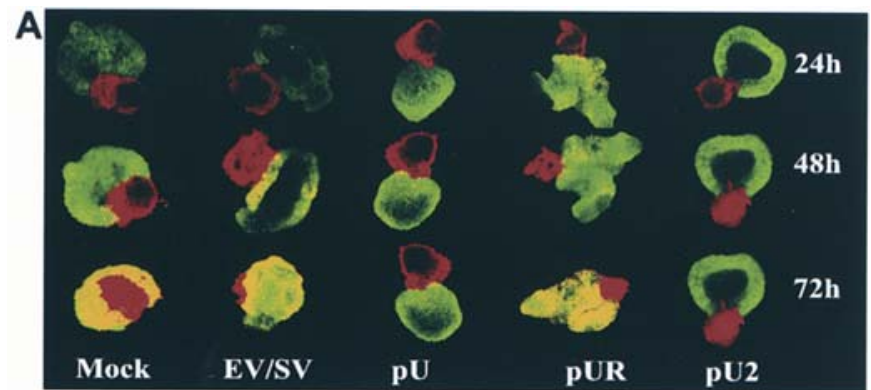

B

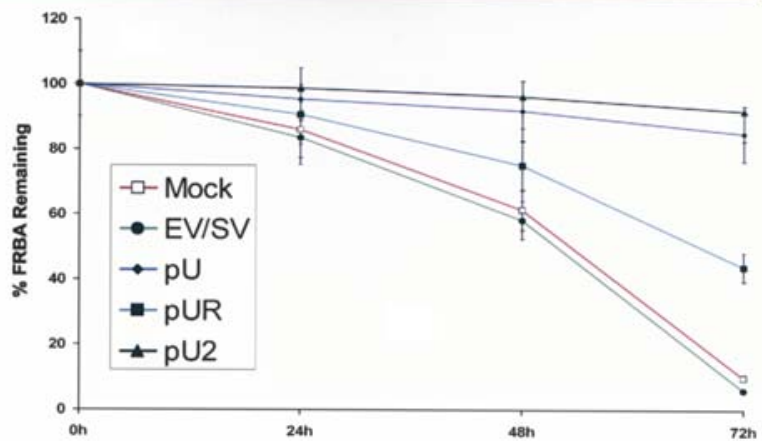

Figure 4. Spheroid invasion in IOMM-Lee cells transfected with mock, EV/SV, $\mathrm{pU}, \mathrm{pUR}$ and pU2. Spheroids of 100-200 microns prepared as described in Materials and methods were transfected with mock, EV/SV, pU, pUR and pU2 and stained with DiL (red fluorescence). These spheroids were then co-cultured with rat brain aggregates stained with $\mathrm{DiO}$ (green fluorescence) obtained from 18-day-old fetal rat brains. Co-cultures were scanned with a laser-scanning microscope at 24, 48 and $72 \mathrm{~h}$ (A). Percentage of FRBA remaining after 24, 48 and $72 \mathrm{~h}$ was quantified and graphically represented (B).

spheroids treated with mock and EV/SV progressively invaded rat brain aggregates, causing almost complete invasion. In contrast, siRNA-transfected spheroids failed to invade rat brain aggregates (Fig. 4A). Quantative determination of the percent of FRBA remaining was determined at 24, 48 and $72 \mathrm{~h}$ after confrontation (Fig. 4B).

pU2 treatment causes regression of subcutaneous tumors. To study whether pU2 can inhibit tumor growth, we examined
A

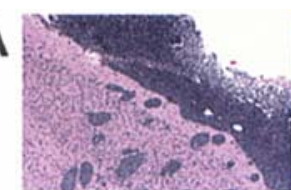

Mock

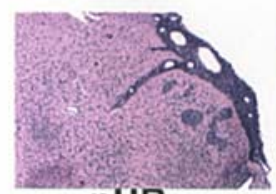

pUR

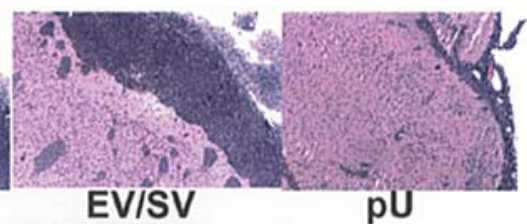

B

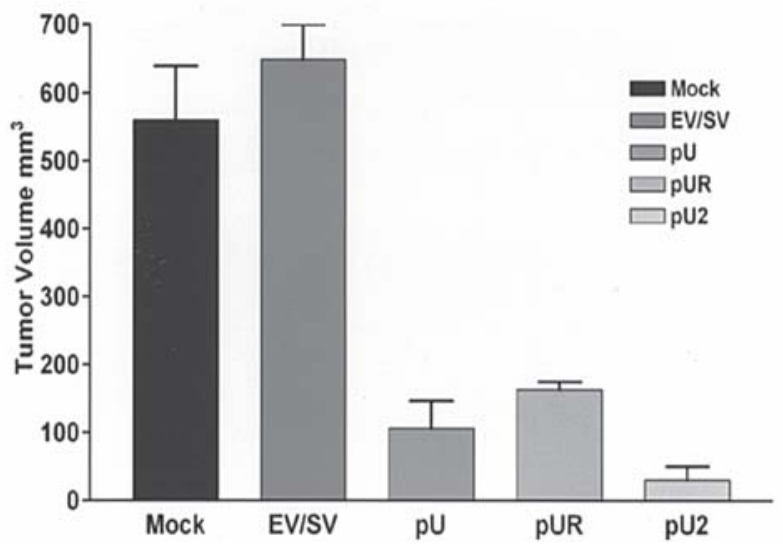

Figure 6. Suppression of intracranial tumor growth by RNAi. $0.5 \times 10^{6}$ IOMM-Lee parental cells or cells transfected with EV/SV, pU, pUR or pU2 were injected intracranially into nude mice. After 4 weeks, the mice were sacrificed, the brains removed and fixed in formaldehyde, paraffin-embedded and sectioned followed by H\&E staining (A). The stained sections were viewed under a microscope and the tumor area determined in serial sections to approximately determine the intracranial tumor volume (B).

the ability of siRNA to inhibit pre-established tumors in nude mice. Subcutaneous tumors were developed by injecting $5 \times 10^{6}$ IOMM-Lee cells into the right flank of female nude mice. When the tumor reached $4-5 \mathrm{~mm}$ in size, the tumors were injected every second day with $\mathrm{pU}, \mathrm{pUR}$ or $\mathrm{pU} 2$ for a
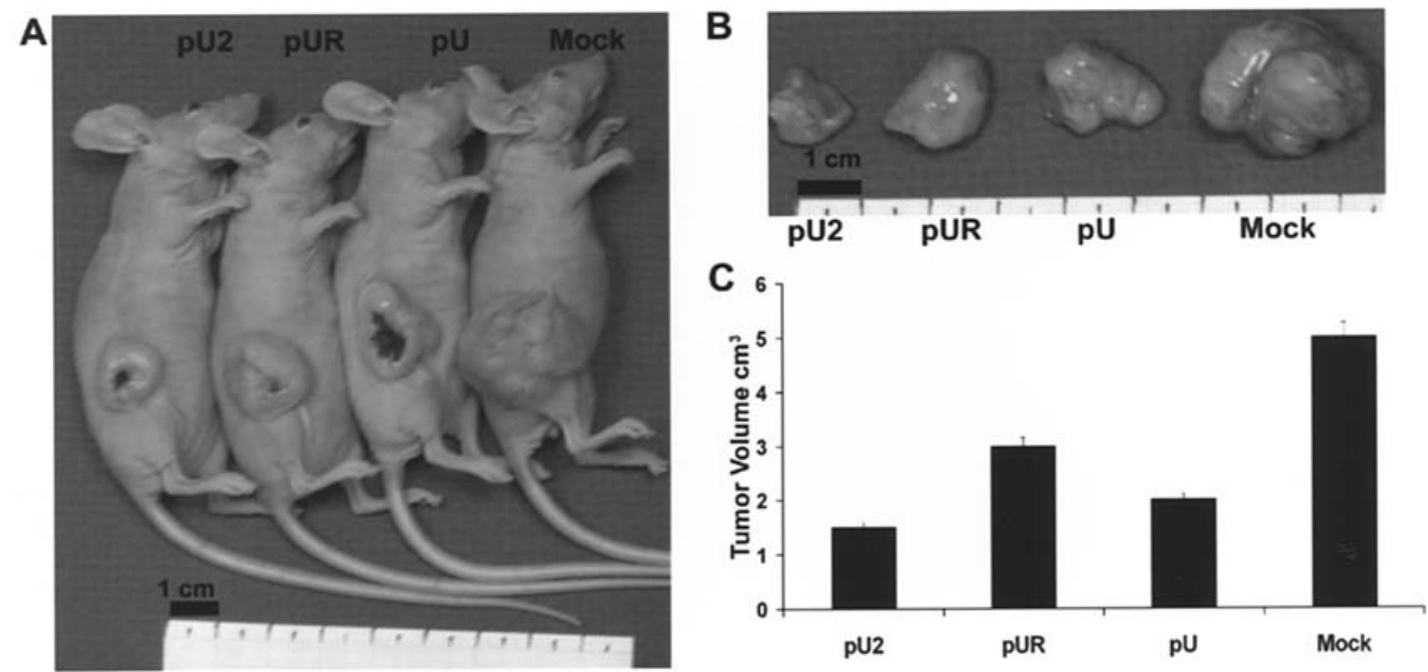

Figure 5. Regression of subcutaneous tumors by RNAi. $5 \times 10^{6}$ IOMM-Lee cells were injected subcutaneously into the right flanks of nude mice. When the tumors reached 4-5 mm in size, pU, pUR or pU2 was injected intratumorally on alternate days (A). A total of five injections were given. Tumors were excised after 4 weeks and photographed (B) and tumor volume was determined (C). 
total of five doses (150 $\mu \mathrm{g}$ of plasmid per dose in $100 \mu \mathrm{l}$ of sterile PBS). Mice were observed for 4 weeks, after which the tumors were excised. Fig. 5A and B shows regression of subcutaneous tumors injected with siRNA as compared to mock- and EV/SV-treated tumors. These results also demonstrate that inhibition of established tumor growth was much higher in mice treated with the bicistronic construct as compared to either of the single constructs. Tumor volume quantification (Fig. 5C) indicated a regression of tumor size in pU2-injected tumors.

Intracranial injections of pU2-transfected IOMM-Lee cells suppress tumor growth in mice. To confirm in vitro studies, we used an intracranial tumor model to assess the potential effects of siRNA-mediated suppression of invasiveness in nude mice. Half a million IOMM-Lee cells transfected with pU, pUR, pU2, and mock and EV/SV were injected intracranially into female athymic nude mice. Mice were sacrificed after 4 weeks. The brain sections of mice analyzed using H\&E showed large spread tumor growth in mice injected with mock and EV/SV. In contrast, mice injected with siRNAtransfected cells showed minimal or no tumor growth, thus proving the effectiveness of RNAi in inhibiting meningioma invasion (Fig. 6A). Semi-quantification of serial tumor sections was performed and shows the regression of intra-cranial tumors in pU2-treated mice (Fig. 6B).

\section{Discussion}

RNAi has opened doors not only as a tool for gene therapy, but also for understanding the basic mechanisms underlying cellular function. RNAi is currently being exploited for its therapeutic potential in cancer, genetic diseases and viral diseases $(38,39)$. Studies have demonstrated that dsRNA shorter than 30 nucleotides can be used for triggering RNAi without activating the mammalian interferon system (40). However, difficulties involving the efficient delivery of RNAi into mammalian cells (41) and the off-target effects (42) persist. Nonetheless, due to the great success of synthetic siRNA in mammalian cell cultures and its function in vivo (43), several laboratories are currently utilizing RNAi to target cancer cells and tumor growth $(44,45)$.

Although meningiomas are some of the most common CNS tumors, they remain understudied in comparison to gliomas. Most meningiomas are resectable with the exception of meningiomas, which are malignant (3-5\%) and atypical $(9,10)$. For these recurring tumors, radiotherapy is not completely effective and no effective chemo-, hormonal or immunological therapies exist. For these reasons, we targeted these tumors with RNAi in this study. As the results demonstrate, we were able to effectively downregulate uPA and UPAR, and thus inhibit tumor growth, invasion and migration.

The characteristic features of any malignant tumor are tumor cell invasion and migration. Cell invasion is due to degradation of the ECM by proteases. These proteases are involved in tumor growth and invasion at both primary and metastatic sites (46), particularly at the invading foci (47). Our previous studies have demonstrated the roles of uPA and UPAR in malignant tumors whose interaction is crucial to invasion. Studies have also shown that using SNB19 antisense clones for uPA (30), uPAR $(35,36)$, Ad-uPAR (31), and Ad-uPA-uPAR (32) as well as RNAi for cathepsin B and uPAR (34) decreased tumor growth and invasion in gliomas.

In this study, as assessed by Western blotting and fibrin zymography, transient transfection of IOMM-Lee cells with pU2 decreased endogenous UPAR levels and uPA activity. In addition, the results of our migration studies showed little or no migration of cells from spheroids transfected with pU2. However, the migration observed in pU- and pUR-transfected spheroids suggests that both $\mathrm{UPA}$ and $\mathrm{UPAR}$ are required for tumor cells to migrate.

Previous studies indicate that uPA participates in signal transduction pathways involved in adhesion and motility, independent of its proteolytic activity (29). UPAR is a glycosyl phosphatidylinositol-linked protein involved in multiple protein-protein interactions (48). UPA mediates cell migration and adhesion through interactions between UPAR and integrins as well as vitronectin $(17,18)$. uPA has been shown to promote physical association between uPAR and $\alpha \mathrm{v} 35$ integrins, which is required for UPAR-directed cell migration in breast carcinoma cell lines. UPA has also been shown to promote cytoskeletal rearrangements as mediated by $\alpha \mathrm{v} ß 5$ integrins (49). Planus et al (50) reported that UPA and UPAR are involved in cellular migration. Our findings confirm that downregulation of UPA and UPAR decreases cell migration, possibly by cytoskeletal alterations.

The acquisition of invasiveness by tumor cells is important for tumor progression. There are several reports indicating the involvement of UPA and UPAR in tumor invasion. Disruption of interactions between these two at the cell surface results in blockage of activation of plasminogen and urokinase, inhibiting the proteolytic cascade required for invasion (51). uPA antibodies and inhibitors have been shown to inhibit tumor cell invasion into the ECM, amniotic and chick chorioallantoic membranes (52-55). uPA antibodies also blocked metastasis in Hep3 human carcinoma cells in chick embryos and inhibited local invasiveness of subcutaneous tumors in nude mice (56). Previous studies in mice lacking the uPA gene showed retarded tumor development in a uPA-deficient environment (57). Our previous studies showed that antisense stable clones of uPA and UPAR were less invasive in in vitro models $(30,35,36)$, as were clones that stably expressed an amino terminal fragment of uPA (ATF-uPA) (58).

In the present study, transfection with pU2 inhibited the invasiveness of IOMM-Lee cells and spheroids in Matrigel invasion and co-culture assays. In particular, downregulation of uPA and UPAR by RNAi significantly inhibited invasion of meningioma cells into surrounding ECM in Matrigelcoated transwells and into fetal rat brain tissue. This lack of invasion might be due to the inability of cells to anchor to the ECM. Hence, our studies confirm the significance of uPA and UPAR in the invasive behavior of meningioma cells

Several studies have demonstrated that uPA antagonist peptides inhibit primary tumor growth in syngeneic mice (55). Kook et al (59) reported that antisense oligonucleotides decreased tumor growth, invasion and metastasis by reducing uPAR levels. Also, the downregulation of uPAR expression using an antisense strategy produced a protracted period of dormancy in human epidermoid cancer cells (60). The use of selective inhibitors of uPA and small, synthetic, cyclic, 
competitive uPA antagonists derived from the binding site of UPAR resulted in reduction of tumor burden (61-63). Adenovirus-mediated downregulation of uPA and UPAR has also been shown to inhibit intracranial tumor growth in gliomas (32).

Our present study demonstrates regression of preestablished subcutaneous tumors and suppression of intracranial tumor growth in nude mice by pU2 when compared to mock and EV/SV vectors. These findings correlate with results from in vitro invasion studies and with studies demonstrating complete suppression of pre-established intracranial tumors by siRNA bicistronic constructs for cathepsin B \& MMP-9 (33) and cathepsin B \& uPAR (34) in gliomas.

In conclusion, the simultaneous downregulation of uPA and uPAR using RNAi successfully reduced meningioma cell invasion and migration in vitro and suppressed intracranial growth in vivo. The high tumor regression ability of the bicistronic construct compared to either of the single constructs suggests that RNAi of the UPA-uPAR system is required for effective therapy. These results indicate great potential for the siRNA-mediated downregulation of UPA and UPAR in therapeutic applications for treatment of malignant meningiomas.

\section{Acknowledgements}

We thank Shellee Abraham for preparing the manuscript and Diana Meister and Sushma Jasti for manuscript review. This study was supported by N.I.H. grants CA75557, CA92393, CA95058, CA116708, and N.I.N.D.S. NS47699, the William E. McElroy Foundation (J.S.R.) and the American Cancer Society (W.C.O.).

\section{References}

1. Elbashir SM, Lendeckel W and Tuschl T: RNA interference is mediated by 21- and 22-nucleotide RNAs. Genes Dev 15: 188-200, 2001

2. Hammond CB, Rackley CE, Fiorica J, Morrison A and Wysocki S: Consequences of estrogen deprivation and the rationale for hormone replacement therapy. Am J Manag Care 6: S746-S760, 2000.

3. Fire A, Xu S, Montgomery MK, Kostas SA, Driver SE and Mello CC: Potent and specific genetic interference by doublestranded RNA in Caenorhabditis elegans. Nature 391: 806-811, 1998.

4. Timmons L and Fire A: Specific interference by ingested dsRNA. Nature 395: 854, 1998.

5. Kennerdell JR and Carthew RW: Heritable gene silencing in Drosophila using double-stranded RNA. Nat Biotechnol 18: 896-898, 2000

6. Yang D, Lu H and Erickson JW: Evidence that processed small dsRNAs may mediate sequence-specific mRNA degradation during RNAi in Drosophila embryos. Curr Biol 10: 1191-1200, 2000 .

7. Westhof E and Filipowicz W: From RNAi to epigenomes: how RNA rules the world. Chem Biochem 6: 441-443, 2005.

8. Zamore PD, Tuschl T, Sharp PA and Bartel DP: RNAi: doublestranded RNA directs the ATP-dependent cleavage of mRNA at 21 to 23 nucleotide intervals. Cell 101: 25-33, 2000.

9. Akeyson EW and McCutcheon IE: Management of benign and aggressive intracranial meningiomas. Oncology 10: 747-756, 1996.

10. Younis GA, Sawaya R, DeMonte F, Hess KR, Albrecht S and Bruner JM: Aggressive meningeal tumors: review of a series. J Neurosurg 82: 17-27, 1995.

11. Arai Y, Kubota T, Nakagawa T, Kabuto M, Sato K and Kobayashi H: Production of urokinase-type plasminogen activator (u-PA) and plasminogen activator inhibitor-1 (PAI-1) in human brain tumours. Acta Neurochir 140: 377-385, 1998.
12. Siddique K, Yanamandra N, Gujrati M, Dinh D, Rao JS and Olivero W: Expression of matrix metalloproteinases, their inhibitors and urokinase plasminogen activator in human meningiomas. Int J Oncol 22: 289-294, 2003.

13. Andreasen PA, Egelund R and Petersen HH: The plasminogen activation system in tumor growth, invasion and metastasis. Cell Mol Life Sci 57: 25-40, 2000.

14. Levicar N, Nuttall RK and Lah TT: Proteases in brain tumour progression. Acta Neurochir 145: 825-838, 2003.

15. Blasi F: Proteolysis, cell adhesion, chemotaxis and invasiveness are regulated by the u-PA-u-PAR-PAI-1 system. Thromb Haemost 82: 298-304, 1999.

16. Parry MA, Zhang XC and Bode I: Molecular mechanisms of plasminogen activation: bacterial cofactors provide clues. Trends Biochem Sci 25: 53-59, 2000.

17. Wei Y, Waltz DA, Rao N, Drummond RJ, Rosenberg S and Chapman HA: Identification of the urokinase receptor as an adhesion receptor for vitronectin. J Biol Chem 269: 32380-32388, 1994.

18. Wei Y, Lukashev M, Simon DI, Bodary SC, Rosenberg S, Doyle MV and Chapman HA: Regulation of integrin function by the urokinase receptor. Science 273: 1551-1555, 1996.

19. Besser D, Verde P, Nagamine Y and Blasi F: Signal transduction in the uPA-uPAR system. Fibrinolysis 10: 215-237, 1996.

20. Irigoyen JP, Munoz-Canoves P, Montero L, Koziczak M and Nagamine Y: The plasminogen activator system: biology and regulation. Cell Mol Life Sci 56: 104-132, 1999.

21. Blasi F: u-PA and cell migration: urokinase receptor as a ligand for a chemotactic G-protein-coupled receptor. Haemostasis 31: $59,2001$.

22. Degryse B, Orlando S, Resnati M, Rabbani SA and Blasi F: Urokinase/urokinase receptor and vitronectin/alpha(v)beta(3) integrin induce chemotaxis and cytoskeleton reorganization through different signaling pathways. Oncogene 20: 2032-2043, 2001 .

23. Jo M, Thomas KS, Somlyo AV, Somlyo AP and Gonias SL: Cooperativity between the Ras-ERK and Rho-Rho kinase pathways in urokinase-type plasminogen activator-stimulated cell migration. J Biol Chem 277: 12479-12485, 2002.

24. Nguyen DH, Webb DJ, Catling AD, Song Q, Dhakephalkar A, Weber MJ, Ravichandran KS and Gonias SL: Urokinase-type plasminogen activator stimulates the Ras/extracellular signalregulated kinase (ERK) signaling pathway and $\mathrm{MCF}-7$ cell migration by a mechanism that requires focal adhesion kinase, Src and Shc. Rapid dissociation of GRB2/Sps-Shc complex is associated with the transient phosphorylation of ERK in urokinase-treated cells. J Biol Chem 275: 19382-19388, 2000.

25. Webb DJ, Nguyen DH and Gonias SL: Extracellular signalregulated kinase functions in the urokinase receptor-dependent pathway by which neutralization of low density lipoprotein receptor-related protein promotes fibrosarcoma cell migration and matrigel invasion. J Cell Sci 113: 123-134, 2000.

26. Blasi F and Carmeliet P: uPAR: a versatile signalling orchestrator. Nat Rev Mol Cell Biol 3: 932-943, 2002.

27. Tran N, Cairns MJ, Dawes IW and Arndt GM: Expressing functional siRNAs in mammalian cells using convergent transcription. BMC Biotechnol 3: 21, 2003.

28. Bugge TH, Kombrinck KW, Xiao, Q, Holmback K, Daugherty CC, Witte DP and Degen JL: Growth and dissemination of Lewis lung carcinoma in plasminogen-deficient mice. Blood 90: 4522-4531, 1997.

29. Schmitt M, Harbeck N, Thomssen C, Wilhelm O, Magdolen V, Reuning U, Ulm K, Hofler H, Janicke F and Graeff H: Clinical impact of the plasminogen activation system in tumor invasion and metastasis: prognostic relevance and target for therapy. Thromb Haemost 78: 285-296, 1997.

30. Mohanam S, Jasti SL, Kondraganti SR, Chandrasekar N, Kin Y, Fuller GN, Lakka SS, Kyritsis AP, Dinh DH, Olivero WC, Gujrati M, Yung WK and Rao JS: Stable transfection of urokinase-type plasminogen activator antisense construct modulates invasion of human glioblastoma cells. Clin Cancer Res 7: 2519-2526, 2001.

31. Mohan PM, Chintala SK, Mohanam S, Gladson CL, Kim ES, Gokaslan ZL, Lakka SS, Roth JA, Fang B, Sawaya R, Kyritsis AP and Rao JS: Adenovirus-mediated delivery of antisense gene to urokinase-type plasminogen activator receptor suppresses glioma invasion and tumor growth. Cancer Res 59: 3369-3373, 1999. 
32. Gondi CS, Lakka SS, Yanamandra N, Siddique K, Dinh DH, Olivero WC, Gujrati M and Rao JS: Expression of antisense uPAR and antisense uPA from a bicistronic adenoviral construct inhibits glioma cell invasion, tumor growth and angiogenesis. Oncogene 22: 5967-5975, 2003.

33. Lakka SS, Gondi CS, Yanamandra N, Olivero WC, Dinh DH, Gujrati M and Rao JS: Inhibition of cathepsin B and MMP-9 gene expression in glioblastoma cell line via RNA interference reduces tumor cell invasion, tumor growth and angiogenesis. Oncogene 23: 4681-4689, 2004.

34. Gondi CS, Lakka SS, Dinh DH, Olivero WC, Gujrati M and Rao JS: RNAi-mediated inhibition of cathepsin B and uPAR leads to decreased cell invasion, angiogenesis and tumor growth in gliomas. Oncogene 23: 8486-8496, 2004.

35. Mohanam S, Chintala SK, Go Y, Bhattacharya A, Venkaiah B, Boyd D, Gokaslan ZL, Sawaya R and Rao JS: In vitro inhibition of human glioblastoma cell line invasiveness by antisense uPA receptor. Oncogene 14: 1351-1359, 1997.

36. Go Y, Chintala SK, Mohanam S, Gokaslan Z, Venkaiah B, Bjerkvig R, Oka K, Nicolson GL, Sawaya R and Rao JS: Inhibition of in vivo tumorigenicity and invasiveness of a human glioblastoma cell line transfected with antisense uPAR vectors. Clin Exp Metastasis 15: 440-446, 1997.

37. Mohanam S, Sawaya R, McCutcheon I, Ali-Osman F, Boyd D and Rao JS: Modulation of in vitro invasion of human glioblastoma cells by urokinase-type plasminogen activator receptor antibody. Cancer Res 53: 4143-4147, 1993.

38. Dillon CP, Sandy P, Nencioni A, Kissler S, Rubinson DA and van Parijs L: Annu Rev Physiol 67: 147-173, 2005.

39. Hannon GJ and Rossi JJ: Unlocking the potential of the human genome with RNA interference. Nature 431: 371-378, 2004.

40. Elbashir SM, Harborth J, Lendeckel W, Yalcin A, Weber K and Tuschl T: Duplexes of 21-nucleotide RNAs mediate RNA interference in cultured mammalian cells. Nature 411: 494-498, 2001.

41. Hamar P, Song E, Kokeny G, Chen A, Ouyang N and Lieberman J: Small interfering RNA targeting Fas protects mice against renal ischemia-reperfusion injury. Proc Natl Acad Sci USA 101: 14883-14888, 2004.

42. Jackson AL, Bartz SR, Schelter J, Kobayashi SV, Burchard J, Mao M, Li B, Cavet G and Linsley PS: Expression profiling reveals off-target gene regulation by RNAi. Nat Biotechnol 21: 635-637, 2003.

43. Song E, Lee SK, Wang J, Ince N, Ouyang N, Min J, Chen J, Shankar P and Lieberman J: RNA interference targeting Fas protects mice from fulminant hepatitis. Nat Med 9: 347-351, 2003.

44. Jiang Y, Goldberg ID and Shi YE: Complex roles of tissue inhibitors of metalloproteinases in cancer. Oncogene 21: 2245-2252, 2002.

45. Wilda M, Fuchs U, Wossmann W and Borkhardt A: Killing of leukemic cells with a BCR/ABL fusion gene by RNA interference (RNAi). Oncogene 21: 5716-5724, 2002.

46. Lochter A, Galosy S, Muschler J, Freedman N, Werb Z and Bissell MJ: Matrix metalloproteinase stromelysin-1 triggers a cascade of molecular alterations that leads to stable epithelialto-mesenchymal conversion and a premalignant phenotype in mammary epithelial cells. J Cell Biol 139: 1861-1872, 1997.

47. Ellis V, Pyke C, Eriksen J, Solberg H and Dano K: The urokinase receptor: involvement in cell surface proteolysis and cancer invasion. Ann NY Acad Sci 667: 13-31, 1992.

48. Waltz DA, Natkin LR, Fujita RM, Wei Y and Chapman HA: Plasmin and plasminogen activator inhibitor type 1 promote cellular motility by regulating the interaction between the urokinase receptor and vitronectin. J Clin Invest 100: 58-67, 1997.
49. Carriero MV, Del Vecchio S, Capozzoli M, Franco P, Fontana L, Zannetti A, Botti G, D'Aiuto G, Salvatore M and Stoppelli MP: Urokinase receptor interacts with alpha(v)beta5 vitronectin receptor, promoting urokinase-dependent cell migration in breast cancer. Cancer Res 59: 5307-5314, 1999.

50. Planus E, Barlovatz-Meimon G, Rogers RA, Bonavaud S, Ingber DE and Wang N: Binding of urokinase to plasminogen activator inhibitor type-1 mediates cell adhesion and spreading. J Cell Sci 110: 1091-1098, 1997.

51. Estreicher A, Muhlhauser J, Carpentier JL, Orci L and Vassalli JD: The receptor for urokinase type plasminogen activator polarizes expression of the protease to the leading edge of migrating monocytes and promotes degradation of enzyme inhibitor complexes. J Cell Biol 111: 783-792, 1990

52. Alonso DF, Tejera AM, Farias EF, Bal de Kier Joffe E and Gomez DE: Inhibition of mammary tumor cell adhesion, migration and invasion by the selective synthetic urokinase inhibitor B428. Anticancer Res 18: 4499-4504, 1998.

53. Holst-Hansen C, Johannessen B, Hoyer-Hansen G, Romer J, Ellis $\mathrm{V}$ and Brunner N: Urokinase-type plasminogen activation in three human breast cancer cell lines correlates with their in vitro invasiveness. Clin Exp Metastasis 14: 297-307, 1996.

54. Jarrard DF, Hansen NM, Patai B and Rukstalis DB: Urokinase plasminogen activator is necessary but not sufficient for prostate cancer cell invasion. Invasion Metastasis 15: 34-45, 1995.

55. Min HY, Doyle LV, Vitt CR, Zandonella CL, Stratton-Thomas JR, Shuman MA and Rosenberg S: Urokinase receptor antagonists inhibit angiogenesis and primary tumor growth in syngeneic mice. Cancer Res 56: 2428-2433, 1996.

56. Ossowski L, Russo-Payne H and Wilson EL: Inhibition of urokinase-type plasminogen activator by antibodies: the effect on dissemination of a human tumor in the nude mouse. Cancer Res 51: 274-281, 1991.

57. Gutierrez LS, Schulman A, Brito-Robinson T, Noria F, Ploplis VA and Castellino FJ: Tumor development is retarded in mice lacking the gene for urokinase-type plasminogen activator or its inhibitor, plasminogen activator inhibitor-1. Cancer Res 60: 5839-5847, 2000

58. Mohanam S, Chandrasekar N, Yanamandra N, Khawar S, Mirza F, Dinh DH, Olivero WC and Rao JS: Modulation of invasive properties of human glioblastoma cells stably expressing amino-terminal fragment of urokinase-type plasminogen activator. Oncogene 21: 7824-7830, 2002.

59. Kook YH, Adamski J, Zelent A and Ossowski L: The effect of antisense inhibition of urokinase receptor in human squamous cell carcinoma on malignancy. EMBO J 13: 3983-3991, 1994.

60. Yu W, Kim J and Ossowski L: Reduction in surface urokinase receptor forces malignant cells into a protracted state of dormancy. J Cell Biol 137: 767-777, 1997.

61. Evans DM, Sloan-Stakleff K, Arvan M and Guyton DP: Time and dose dependency of the suppression of pulmonary metastases of rat mammary cancer by amiloride. Clin Exp Metastasis 16: 353-357, 1998.

62. Sato S, Kopitz C, Schmalix WA, Muehlenweg B, Kessler H, Schmitt M, Kruger A and Magdolen V: High-affinity urokinasederived cyclic peptides inhibiting urokinase/urokinase receptorinteraction: effects on tumor growth and spread. FEBS Lett 528: 212-216, 2002.

63. Sturzebecher J, Vieweg H, Steinmetzer T, Schweinitz A, Stubbs MT, Renatus M and Wikstrom P: 3-Amidinophenylalanine-based inhibitors of urokinase. Bioorg Med Chem Lett 9: 3147-3152, 1999. 